\title{
Lived Experiences of Palestinian Patients With COVID-19: A Multi-center Phenomenological Study of Recovery Journey
}

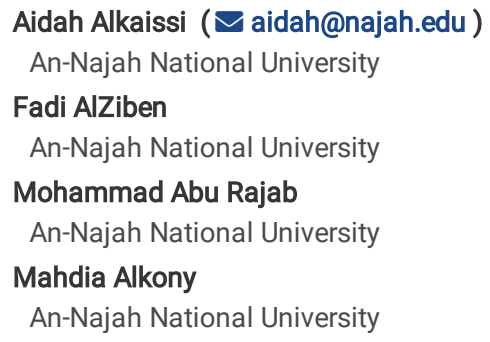

\section{Research Article}

Keywords: COVID-19, SARS-CoV-2, Experiences, Quarantine, Coping, Stigma, Palestine

Posted Date: August 30th, 2021

DOI: https://doi.org/10.21203/rs.3.rs-837572/v1

License: (c) (i) This work is licensed under a Creative Commons Attribution 4.0 International License. Read Full License

Version of Record: A version of this preprint was published at BMC Public Health on March 9th, 2022. See the published version at https://doi.org/10.1186/s12889-022-12868-9. 


\section{Abstract}

Background: Exploring lived experiences of recovered COVID-19 patients might have scientific, social, and policy relevance that apply to the healthcare infrastructure. This multi-center phenomenological study was conducted to explore lived experiences of Palestinian patients who recovered from COVID-19.

Methods: In this qualitative study, a phenomenological descriptive approach was used. A purposive sampling technique was employed to select the study participants. Semi-structured qualitative interviews were conducted with patients who recovered from COVID-19 $(n=20)$. The transcripts of the audio recorded interviews were analyzed by using Giorgio's phenomenological analysis method.

Results: Semi-structured interviews were conducted with 14 male and 6 female participants. The age of the participants ranged from $25-50$ years. Nine themes and multiple subthemes emerged from the qualitative data. The themes were relevant to patient's feelings about the experience, mental issues, social discriminations/stigma, symptoms, life in isolation, using supportive treatment, personal preventive measures, social support, and life after recovery.

Conclusion: Survivors who were interviewed in this study recounted devastating experiences with regard to their mental health, social stigmatization, feeling guilt, shame, and hesitant to regain contact with others. Mental health issues should be addressed as a part of the care plan for patients with COVID-19. More studies are still needed to investigate if introducing mental healthcare providers to the care team of patients with COVID-19 can improve the experiences of the patients.

\section{Background}

In 2019, a new coronavirus disease (COVID-19) was identified as the causative agent of an outbreak of respiratory disease that originated in Wuhan, China. Afterwards, the virus spread to several other countries around the world and the World Health Organization (WHO) has officially declared this global outbreak as a pandemic [1]. The virus is transmitted through direct and indirect contact with infected persons and contaminated objects. Person-to-person transmissions occur mainly during close contact with an infected individual, contact with droplets produced by coughing, and/or contact with droplets produced while sneezing and talking. Indirect transmission occurs by touching contaminated surfaces or objects and then touching the face. Although the virus is more contagious in the first days after the onset of symptoms, asymptomatic patients can also spread the disease [2,3].

The full spectrum of COVID-19 infection ranges from subclinical self-limiting respiratory disease to severe progressive pneumonia with multiple organ failures and death. According to studies and reports, more than $80 \%$ of patients remained asymptomatic and $15 \%$ of the patients developed mild symptoms [2, 4]. Fever, cough, dyspnea, myalgia, and fatigue were the most commonly reported symptoms of the disease.

Exploring lived experiences of healthcare providers during the ongoing pandemic has received considerable attention [5-7]. As the pandemic is still unfolding, exploring the lived experiences of the patients would also be interesting. In recent studies, survivors of COVID-19 recounted distressing mental health problems that they experienced during isolation periods $[5,6]$. Other studies have revealed how COVID-19 patients managed their emotions within the isolation settings [8].

Awareness of the lived experiences of recovered COVID-19 patients could be informative to decision makers who might want to design interventions to improve the physical environment and delivery of care/support to reduce the negative consequences that could be brought about by the isolation period. Considering resurgence of the pandemic in different geographical regions around the world, there is still an increasing need to shed more light into the lived experiences of the survivors of COVID-19, understand the effects of the isolation period on their mental health, and learn from their experiences [5, 6]. This might help decision makers improve isolation environments of future patients.

In Palestine, patients with confirmed COVID-19 infection are destined for isolation either in a healthcare center designated for COVID-19 patients or at their homes. Little is known on the lived experiences of patients who survived COVID-19 in Palestine. This phenomenological study was conducted to explore lived experiences of Palestinian patients who recovered from COVID-19. The study shed light on the real-world experiences of the patients during the isolation period. Findings of this study might have scientific, social, and policy relevance that apply to the healthcare infrastructure in Palestine and other developing countries.

\section{Methods Study design}

In this qualitative study, a phenomenological descriptive approach was used [9]. In phenomenological psychology, accurate description of human experiences is produced through interviews with the participants $[9,10]$. Phenomenological approaches are commonly employed to describe lived experiences and explore perspectives of the participants with regard to a phenomenon of interest [11]. In this study, the phenomenon of interest was lived experiences of Palestinian patients while being isolated as a result of infection with COVID-19. During the interviews, lived experiences of the participants were explored after recovering from the infection. In this qualitative phenomenological study, a holistic approach was followed to understand how the experiences of the participants were contextually formed, influenced, and maintained during both infection and isolation periods. This study was conducted and reported in adherence to the consolidated criteria for reporting qualitative research (COREQ). Adherence to the checklist is provided in Supplementary Table S1.

\section{Participants}


A purposive sampling technique was employed to select the study participants. The participants in this study were Palestinian patients with confirmed COVID19 infection who were isolated either in their homes or in healthcare centers designated for patients with COVID-19. The study participants were identified through personal contacts from the community after learning about their infection with COVID-19. The inclusion criteria were as follows: 1 ) being at least 18 years old, 2) tested positive for COVID-19 using the standard PCR, 3) completed an isolation period of at least 2 weeks, and 4) providing an informed consent to participate in the study. Patients who reported active or past history of psychiatric disorders and those with severe cognitive impairments were excluded. The study participants were informed that this study was being conducted to understand their lived experienced during the isolation period. The participants were assured that this was a scientific research and the researchers had no personal interests to influence the outcomes of the interviews.

The sample size needed for this study was informed by previous phenomenological studies [12]. Thematic saturation point was used to determine the sample size. We assumed that at least 800 min of interview time would be sufficient to generate qualitative data that would allow achieving thematic saturation. Assuming an average interview time of $40 \mathrm{~min}$, at least 20 interviews would be needed in this study.

\section{Data collection}

As the study was conducted during the ongoing pandemic, qualitative data were collected through semi-structured interviews with the participants through a proprietary videotelephony software program (Zoom, San Jose, California) in full compliance with the physical distancing instructions. The semi-structured interviews were conducted with the help of an interview guide. The probing questions were developed after a literature review and consultations with the experts in the field. Before the interviews were conducted, the interview guide was pilot tested to ensure using relevant terminologies and generation of sequential data. The questions in the interview guide were related to the symptoms, diagnosis, time in isolation, and physical, psychological, and social health of the participants. The interview guide is provided in Supplementary Table S2. The participants were also asked about how they managed their symptoms. After establishing contact, the scope and objectives of the study were explained to the potential participants. A verbal consent was obtained from each participant before the interview. The interviews were conducted by 4 researchers ( 2 male and 2 female) who were employed by the main teaching university in Palestine at the time of the study. Of the researchers, 3 had Master of Science degrees (MSc in nursing) and 1 had a doctorate (PhD in nursing). The researchers were trained as nurses and had experience in interviewing patients to obtain health information. To ensure data saturation within the theoretical background and framework of analysis, each interview lasted for at least $40 \mathrm{~min}$.

The study participants were interviewed while they were at home. Before each interview, sociodemographic characteristics of the participants like age, gender, place of residence, marital status, number of children, number of family members, educational level, smoking status, occupation, and monthly income were collected. We also collected information on the presence of cardiovascular, digestive, endocrine, pulmonary, and other diseases.

The interviews started with an open-ended question on how the patient felt about having contacted COVID-19 and recovered from the disease. The participants were asked to recount their lived experiences from the time they received their diagnosis through recovery (Supplementary Table S2). Whenever needed, prompts were used to clarify, examine, and/or unpack some answers/experiences. The interviews were conducted during the month of February 2021.

Planning considered providing adequate psychological interventions to participants who might exhibit emotional issues during the interviews to prevent potential psychological harm. The study participants could withdraw their consent at any time. Throughout the study, the researchers remained neutral with regard to the outcomes of this study while collecting, analyzing, and reporting data. To ensure authenticity of the data collected during the interviews, the interviewers actively listened to the participants, clarified information whenever needed, and unconditionally accepted the information/experiences described by the participants. As the interviews were recorded, field notes were seldom taken.

\section{Data analysis}

All interviews were recorded and transcribed verbatim within $24 \mathrm{~h}$ of each interview. The transcripts were analyzed using Giorgio's phenomenological approach [9]. The transcripts of the interviews were coded and analyzed for meaningful units by the four researchers independently. The transcripts were read by the researchers multiple times and a number of established techniques were used to strengthen the accuracy of the qualitative analysis [13]. These included close and repeated reading of transcripts, regular discussion about new results among the research team members using disagreements between researchers to request a search for confirmation or rejection of data, and triangulation of results from individual interviews with individuals. The transcripts were read multiple time to gain an overall understanding of the contents. For each transcript, summaries were prepared. The summaries of the interviews were used to identify early themes. The preliminary results were compared between the four researchers and conflicting results were discussed. The transcripts were reviewed again to establish relationships and overlaps between the identified themes, subthemes, and patterns. Bracketing was used to avoid bias due to preconceptions [14]. The collected data were grouped into themes, subthemes, and patterns by the four researchers independently. Theme contents were compared and matched. Conflicting opinions were discussed and resolved among the research group. The data analysis process consisted of four consecutive steps where each step was a prerequisite for the next step $[9,15]$.

\section{Ethics approval and consent to participate}

The study was conducted in adherence to the ethical consideration in the Declaration of Helsinki and the international guidelines of medical research [16]. AnNajah National University's Institutional Review Board (IRB) approved the procedure of protection of human subjects that was followed in this study. The participants provided verbal consent before they were interviewed. Confidentiality of the participants was maintained and no information leading to the identification of the participants was disclosed. No body other than the researchers had access to the recorded materials. All data related to this study were stored in a closed cabinet.

\section{Results}


In this study, semi-structured interviews $(n=20)$ were conducted with 14 male and 6 female participants. The total duration of the interview time was 998 min $(16.6 \mathrm{~h})$. The age of the participants ranged from 25-50 years. The participants were recruited from different geographical regions of Palestine. The participants were diversified in terms of marital status, number of offspring, family size, educational level, smoking status, occupation, income, and having other comorbidities. The detailed sociodemographic and health characteristics of the participants are shown in Table 1.

The qualitative data collected during the interviews were grouped under nine broad themes. Multiple subthemes have also emerged from the broad themes. Detailed themes and sub-themes are provided in Supplementary Table S3.

\section{Source of infection}

One of the participants thought they caught the virus while visiting a dental clinic. Another participant caught the virus while meeting a friend during a short travel. The rest of the participants either caught the virus from a spouse or were not certain of their source of infection.

"I picked up corona virus from the dental clinic" (P1)

\section{Theme one: Feeling about the infection}

\section{Subthemes: Awful, hard, shocked, end of life, feeling guilty, but I caught it}

All of the participants stated that they felt shocked to learn that they tested positive for the virus. Receiving the diagnosis was met with anxiety, shock, and doubt. The participants described receiving the diagnosis "was awful". One of the participants shared:

"It was a bit awful and hard that I actually got infected by it... I couldn't believe I had actually contracted the virus... that I tested positive" (P2).

All the participants reported doubt with regard to the symptoms as the symptoms were mild and non-specific. The symptoms typically included sore throat, low-grade fever, muscle ache, nausea, and vomiting. When the participants visited their physicians, the first diagnosis was either common cold or seasonal flu. One of the participants stated:

"I had symptoms of pain in the throat and a high temperature, and the doctor told me that it was not corona and prescribed an antibiotic and a fever reducer, and on the third day, when I began to lose the sense of smell and taste, I did a corona test, and it was positive..... Honestly.... I was shocked and felt that this is the end of life" (P15)

Another participant declared:

"I did not complain of any symptoms of illness, but because of my husband's illness I took the test and it was positive, and on the third day, signs of the disease began to appear, such as a high temperature up to 39.5, nausea, vomiting, pain in the upper back and legs, a strong desire to sleep and emaciation" (P4)

The participants stated that it was hard for them to believe that they have contracted COVID-19 as they reported adherence to hygiene practices, wore masks, and gloves when the pandemic was declared. One of the participants stated:

"I thought I would not get it [COVID-19], but eventually I did. But I took precautions. I wore masks, gloves, I felt confident that I was taking all the precautions, and I did not think I could catch it but I caught it" (P 1)

The participants expressed negative feelings and emotions as they experienced infection with COVID-19. The participants expressed concerns that they might spread the infection to others, especially, their family members. One participant expressed:

"I was the first person to contract the virus and passed it to my wife and children, I feel guilty" P5.

\section{Theme two: Mental issues as result of experiencing infection with cOVID-19}

\section{Subthemes: Negative and positive mental health issues}

The participants reported experiencing negative as well as positive mental health issues during their experience. On the negative side, the participants reported experiencing feelings like anger/frustration, depressed mood, loneliness, boredom, had nightmares, feared death, felt guilty, felt imprisoned, and were worried about the health of their family members. One of the participants shared that they felt guilty and embarrassed as they passed the virus to other people. The participant was prescribed antidepressants by their physician. One participant shared:

"Sometimes I feel like I am in jail" (P1)

"It was a nightmare and in fact every time I slept, I had nightmares and it was the worst period of my whole life" (P6)

"I feel guilty because of the potential risks my family would be exposed to, from catching the virus from me" (P19)

"When I got out of isolation after 23 days, I felt free and as if I was in a prison without jailers" (p6).

"Anxiety about family members being infected and worrying about family members being left alone" (P1) 
"I could not sleep, I was afraid to die without being able to see my family and friends, despair overcame me." (P17)

"I am feeling of guilt and embarrassment from thoughts of having infected people she came in contact with"(P2)

On the other hand, the participants reported positive experiences with regard to their mental health. One of the participants expressed feeling closer to God through prayers and reading the Holy Qur'an as they recovered from the infection. Other participants reported reading more books and receiving support from their relatives and co-workers made them feel loved, improved their mood, and helped them during the isolation period. One of the participants reported changing their perceptions and improved their satisfaction with their life conditions. One of the participants expressed:

"I was always in touch with my family and my wife and being assured of this, which helped me get past the stage safely" (P11)

Another participant stated:

"This disease made me know that my loved ones are increasing and that the people who loved me were standing next to me all the time, communicating with me and relieving of my pain and weakness, and they were part of the treatment and raised my spirits"(P6).

Another participant expressed:

"I do not lose hope in God. I was very happy when I learned that I was cured and that the result of Covid 19 was negative. Praise be to God always and forever". (P13)

Another participant added:

"My wife and I were tested positive for COVID and we stayed in isolation for 21 days. During this period I relieved the pressure of work, organized my life and came out of isolation in a good mood and imprisonment with my beloved is sweet" (P10)

Theme three: Anticipated social discrimination and stigma

Subthemes: Out casted, changed the road to avoid contact with me, Burning the trash can, "House of Corona", accusation of guilt, Get away from me, public advertising via social networking sites and mosque's headphones, faced backlash.

In this study, the participants reported experiencing social discrimination and stigma in their communities. Some of the participants reported having to take longer walking routes to their homes as they were not allowed by the community members to walk in the main streets. One of the participants expressed concerned that in the future they and their family members would be outcaste.

One of the participants recounted that the neighbors burned the trash can in front of their home as the ambulance came to transfer a patient to the hospital. Even after recover, the participants reported people avoiding any contact with them through changing lanes to keep themselves away from a recovered COVID19 patient. As one participant shared:

"People were burning a trash can in the street in front of my house where I put the waste when they noticed that the ambulance was coming to take me to the COVID-19 facility" (P1)

The participants reported that discrimination and stigma continued even after their recovery and testing negative. One participant continued:

"I was being stigmatized by being linked to a confirmed case" (P1)

"I faced backlash and harsh comments from the public and even those who know me" (P4)

"The situation was when I came back on my turn (meaning after recovery), many of the employees avoided dealing with me or touching anything about me and this thing made me feel that I was an outcast" (P6)

"After I recovered and got off, I walked in the street, and people used to change the road to avoid me and were away from me" (P20)

"My wife and my four children they caught corona like me. In a situation I will never forget for the rest of my life ... the neighborhood where we live, they mark my house with plague, "a corona house", and unfortunately no one approached the house or deal with us, and this issue made us feel isolated and bullied. But God forgives them" (P16)

"Some blamed me for being ill of Corona virus and they thought my illness was because I did not take adequate precaution of prevention and safety" (P9)

"The situation that bothered me the most was what some relatives said to me: Get away from me, do not come near me" (P10)

"It was announced on social media the names of those infected with Corona before informing stakeholders about it. We knew from people that we were infected. (P11)

Theme four: The physiological symptoms as matters of experience

Four subthemes: Respiratory symptoms, gastrointestinal symptoms, neurological symptoms and ophthalmologic symptoms 
The symptoms experienced by the participants were reported as dry or purulent productive cough, fever, shortness of breath, loss of smelling and tasting, cold like symptoms, symptoms similar to seasonal flu, dry throat, thirst, nausea, vomiting, loss of appetite, muscle ache, fatigue like a rag, intolerable headaches, red eyes, blurred vision, heart palpitation, sweating at night, dizziness, feeling pressure in the ears, insomnia, have frequent night time awakenings, and feeling restless. In this study, all participants experienced respiratory symptoms. The participants shared:

"I had dry constant cough, fever and shortness of breath ...... I got severe myalgia, I couldn't lift arm, hard to get out of bed...body aches...sore throat, difficulty breathing and especially loss of sense of smell and taste" (P17)

"I've felt cold-like symptoms at the beginning before diagnosed with COVID-19" (P2)

"I suffered from a high fever and pain that tortured every part of my body..... kept on coughing specially in the afternoon. I could not sleep at all...It lasted for two days" (P20)

"Last few days for me have been awful. Began to lose the sense of smell and taste. Very high temperature around 39, cough, sore throat, breathlessness, nausea, and vomiting" (P14)

"Utterly exhausted, with whole-body ache and feeling weak in the muscle, feeling tired" (all the participant)

"I am feeling fatigue is literally like a rag. I cannot stay awake longer, I have to go to bed" (P13)

"I feel that my legs are fallen and I cannot rest on them" (P11)

"I feel pain in the upper part of the back, especially the shoulder area. I feel that my shoulders are flared" (P4)

"I have cough which was productive associated with brown purulent mucous" (P2)

"Headache started in upper frontal part (P4), occipital (P1), frontal (P3) severe intolerable headache deeply inside the head" (P2)

"The first hint which could necessitate a coronavirus test is very dry throat feeling like a burn especially at night. The worst sore throat you can imagine, water doesn't quench the thirst" (P19)

"Most of those who saw me asked me why your eyes are red" (P5)

"I did not feel anything because breathing difficulties were the most controlling for me ... As for what I remembered about the symptoms.... I expected to die of suffocation" (P13)

"I suffered from Stomach ache, diarrhea, dizziness and Blurred eyes" (P15)

Theme five: Life in isolation- Coping with adversity

Subthemes: feelings of depression and loneliness, feeling bored and uncertain about the future, keep busy, lack of direct social interaction, keep in touch and keep socially active, keep moving, practice spiritual rituals

The participants reported that they felt loneliness, depressed, boredom, and uncertainty with regard to the length of the quarantine period. The participants shared:

"I am Feeling lonely and depress due to losing touch with others" (P1)

"Despite the boredom and ambiguity of the quarantine period but I was willing to stay to prevent others from becoming infected" (P3)

"The more time I spent, I read and browsed the various websites to find out more information about the disease, treatment methods, recent studies and some time to read the Quran and prayer" (P9)

The participants stated that they have practiced social distancing and obeyed the "stay at home" orders after recovering. The participants reported that they limited their social interactions. One of the participants stated:

"I strictly prohibited any interaction with others" (P20)

\section{Theme six; Supportive treatment, herbs, and rituals}

\section{Subthemes: Medical treatment, prone position, Prayer mode- prostration, herbal medicine, Immunity booster, washing down the virus.}

In absence of preventive and therapeutic agents for COVID-19, the participants turned to herbal medicines and rituals. The participants shared:

"I used bronchodilator vapors (Ventoline (Nebulizer), Atrovent (Nebulizer), cortisone drugs, painkillers, Azithromycin (antibiotics), Paracetamol" (all the participant)

"I used prone position, it is the position to be in to relieve cough especially during the night" (P1, P4) 
"I used Prayer mode- prostration to relieve the dyspnea with good effect" (P5)

"I used grind Black Seed (Habbat Al-Barakah) with honey, boiled dry flowers, anise grain, chamomile, curcumin in the food, lemon and ginger to relieve cough" (all the participant)

"Fruits and juices are important and healthy diet also to build immunity" (all the participant)

"If there is a virus in the body. The virus stays in the throat for four days ... so I washed it with water pipes with high force to send the virus to the stomach" (P3)

"I was eating healthy food, consuming a lot of water, and using various types of natural herbs" (P5)

Theme seven: Personal preventive measures and population-level strategies.

Subthemes: social distancing, the use of masks, sanitizers, and hand washing, eating healthy food, and drinking a lot of water

Recommended precautions of COVID-19 were designed to reduce/eliminate transmission of the virus. These include frequent hand washing, wearing masks, gloves, practicing physical distancing, avoiding/minimizing physical contact, covering the mouth and nose while coughing, and avoiding contamination of the face with unwashed hands. The participants stated that wearing masks, washing hands or using disinfectants, and practicing social distancing can help prevent transmission of the virus.

Masks are an important measure of suppressing transmission and saving lives. Masks should be used as part of a comprehensive "Do it all!" -method including physical distance, avoid crowdedness, avoid closed contact settings, good ventilation, cleaning of hands, covering with sneezing and coughing and more. Masks can be used either to protect healthy people or to prevent transmission. The participants shared:

"One should follow the advice and self-isolate. Protect your colleagues, protect your friends and family, and protect yourself" (P1)

"The use of masks, sanitizers, hand washing, social distancing and proper locking would help prevent the disease" (P4)

\section{Theme eight: Perception of social support and health protective behaviors}

\section{Subthemes: social support by the wife, family, dear and close friends, loved ones raising spirits, lift spirit in an exaggerated way.}

Perceived social support is a personal subjective assessment of the availability and adequacy of resources and reactions from one's social networks. Social support received referred to the objective assessments of the personal social contacts and their related functions. The participants shared:

"My wife used to bring me various food and drinks, organize times for my treatment and take care of me in all aspects of life" (P2)

"I was always in touch with my family and my wife and being assured of this, which helped me get past the stage safely" (P1)

"My fiancée used to come and talk to me from behind the window panes, and this comforted me a lot" (P3)

"When they took the second test, and the result was negative, I felt that we were re-created and that this disease despite its difficulty was a god with positive social effects that allowed us to meet as a family and feel our love for each other" (P5)

"This disease made me know that my loved ones are increasing and that the people who loved me were standing next to me all the time, communicating with me and relieving of my pain and weakness, and they were part of the treatment and raised my spirits" (P6)

On the other hand, some people tried to lift the spirit of the participants in an exaggerated way. This was associated with negative consequences. One of the participants stated:

"Some people who communicate with me made me feel like I was going to die and tried to lift my spirits in an exaggerated way. This thing made me think that I feel that the problem is very difficult and that they know something I do not know" (P15)

\section{Theme nine: Life after recovery}

\section{Subthemes: Fear of relapse, not expecting to return to normal life, scared, released.}

All participants who took part in this study expressed hope to make a complete recovery. The participants stated that experiencing infection with COVID-19 led to adopting of new behaviors like adherence to hygiene practices. Additionally, the participants reported adopting more healthy lifestyle to improve their immunity. Some participants expressed fear of re-infection. One participant shared:

"Actually, the main thing I'm worried about getting the disease again. I do not know if my body builds antibodies, I do not know if the disease damages other organs in my body, I am worried about fertility" (P1)

While some of the recovered participants felt comfortable to go out after their quarantine period, some participants expressed hesitations to go out. Some of the participants felt hesitant to meet people after completing their quarantine period and testing negative for the virus. The participants shared: 
"I was not happy because the symptoms were not over and I felt that I could relapse and return to the same suffering at any time. I already felt tired today, even though it is more than 25 days after the recovery of the disease" (P6)

"A rare experience and pray to God not to return back to me. For the first time in my life I experienced such suffering. I did not expect to return to my normal life" (P6)

"I felt it was strange that I would go back and meet people, see the street, go back to my work ... I felt a little scared, especially since I still had difficulty breathing" (P12)

"Release ... As if I was in prison and I was pardoned .... I swear to God, it was good news to be released" (P16)

\section{Discussion}

In this phenomenological study, survivors of COVID-19 recounted their lived experiences from the moment they learned about their infection to the aftermath this experience. Survivors who were interviewed in this study recounted devastating experiences with regard to their mental health, social stigmatization, feeling guilt, shame, and hesitant to regain contact with others. Findings of this study were consistent with those that reported mental health issues among survivors of COVID-19 [6].

\section{Mental health issues as a result of the experience}

In this study, the participants reported experiencing anxiety, panic attacks, and fear of death as a result of their COVID-19 infection. Findings of this study were consistent with those reported by Wang et al on the high prevalence of anxiety and depression among survivors of COVID-19 [17]. Probably, these issues were augmented by the misconceptions and lack of understanding of the nature of the disease, the environment in the isolation settings, and fear of transmitted the virus to others. Some of the participants expressed feeling of remorse as they thought they could have transmitted the virus to other members of their families. Findings of this study were consistent with those reported by Cheng et al as well as other studies among SARS survivors [18, 19]. Our findings might indicate that psychological support and direct communication might be needed to reduce the deleterious consequences of these feelings on the mental health of COVID-1 survivors. Previous studies have also shown that patients recovering from a disease or a life-threatening incident while in isolation/quarantine are at a higher risk of developing acute mental disorders [20,21].

It is noteworthy mentioning that due to the qualitative nature of this investigation; it is unclear whether these emotions were a result of the isolation/quarantine environment or the underlying pathology of the disease. In previous studies, survivors of COVID-19 reported feeling depressed, overwhelmed, and had traumatic memory while recovering from infection [6]. Isolation is known to preclude family support. If not appropriately addressed, this might exacerbate negative psychological consequences among COVID-19 survivors [22]. During SARS outbreak, findings reported by Hawryluck et al revealed negative consequences of isolation among the survivors [23]. As isolation is unavoidable in highly contagious diseases like COVID-19, findings of this study indicated the need to improve isolation environments, provision of physiological support to patients and survivors, improving communication channels between the patients and their beloved ones [24]. Access to the internet, social media, and other telecommunication modalities could be helpful. Additionally, mental health specialists should become aware the anxiety, insomnia, shame, rage, resentment, and internalized stigma are major issues among COVID-19 survivors that they might need to address [6].

Findings of this study as well as those of previous studies may indicate a need to improve isolation environments. The physical features of the isolation settings may significantly impact perceptions of the patients and their experiences [25]. Isolation settings with sufficient space to walk around and availability of large windows to provide the patients with the opportunity to related to spaces around their isolation settings might help reduce the negative psychological consequences of the isolation period. Findings of this study also indicated that there was a need to provide psychological support to patients with COVID-19 during their isolation period on a regular basis $[6,26]$. These findings were consistent with the recommendations of the WHO in which psychological issues were needed to be considered among the general public during the pandemic [27]. Additionally, psychological first aid for patients with COVID-19 who are admitted to hospitals was addressed in recent research $[28,29]$. It was suggested that hospitals/healthcare centers to which COVID-19 patients are admitted need to offer mental health support and mental healthcare providers should be involved in screening patients with COVID-19 [30]. Additionally, the mental healthcare providers might need to address issues brought about by the isolation period. As symptoms might subside within few days, mental health issues might become the prominent issues the healthcare providers need to address. However, addressing mental health issues is not part of current treatment protocols of COVID-19. Taken together, findings of this study as well as those of previous studies might indicate that mental health issues should be added to the updated treatment protocols [31].

\section{Symptoms experienced by the participants}

The symptoms reported by the participants in this study were consistent with those reported in previous studies conducted elsewhere [32-34]. Respiratory symptoms were commonly reported among patients with COVID-19 [35, 36]. Additionally, fever and dry cough were also reported as common symptoms. Dyspnea, nausea, vomiting, diarrhea, and abdominal pain were also reported [32, 36, 37]. Huang et al. (2020) reported that fever is the most common manifestation reported by patients ( $98 \%)$, followed by cough (76\%), myalgia or fatigue (44\%), sputum production (28\%) and headache ( $8 \%$ ) [4]. Previous studies reported that symptoms and their severity might vary significantly among COVID-19 patients [17, 38]. This might indicate that the treatment plan should be individualized to meet the needs of the patient. 


\section{Anticipated social discrimination and stigma}

Findings of this study indicated that the participants were subjects to social stigma and discrimination. Stigma and discrimination were previously shown to result in negative self-perception and lower rates of disclosure of infection [39]. This might jeopardize the health of the patient and the society at large. In this study, many of the recounts could convey feelings of shame and guilt that were consistent with social stigma [40]. Previous studies have shown that the stigmatized groups can be subjects to social avoidance, physical violence, and denials of housing and care [41, 42]. Taken together, findings of this study may indicate a need for interventions to reduce social stigma and discrimination and encourage disclosure of infection. In previous outbreaks of infectious diseases, stigma was also reported as a major issue and isolated patients were subjects to rejection from people in their local neighborhoods [43]. Survivors also reported differential treatment by others, avoidance, and withdrawal of social invitations $[44,45]$. The severity of stigmatization was associated with the length of the isolation period $[23,46]$.

\section{Life in "isolation" coping with adversity}

Quarantine is the separation and restriction of movements for people who are potentially exposed to an infectious disease to determine if they become infected or not. This is often practiced to reduce the risk of infecting others. By definition, quarantine differs from isolation which is defined as separation of individuals who have been diagnosed with an infectious disease from people who are not infected. However, the two terms are often used interchangeably [47]. Quarantine is often an unpleasant experience for those who went through it. Separation from loved ones, loss of freedom, uncertainty about disease status, and boredom can sometimes have dramatic psychological consequences [48].

During the COVID-19 threat, quarantine was used as a public health tool to prevent the spread of this contagious disease. Based on clinical examinations, the incubation period was generally 1-14 days and (usually 3-7 days) [49]. The majority of the participants completed an isolation period of 14 days. Some of the participants also completed longer isolation period for up to 21 days. Analysis of the qualitative data collected in this study showed that the participants experienced fear as a result of the isolation/quarantine period. Xiao et al. reported that isolated/quarantined patients distanced themselves from each other and were more likely to experience negative emotions in the absence of interpersonal communication [50]. In addition, our results were consistent with the psychological effects such as fear of isolation/quarantine on individuals with fever during the SARS period [44, 51]. In our study, all participants expressed fear during the isolation/quarantine period. This feeling can probably be attributed to the uncertainties with regard to the consequences of COVID-19 infection and the lack of freedom and the company of others. Xiang et al. (2020) recommended that regular, accurate, and up-to-date information on COVID-19 should be provided to patients and the general public to alleviate feeling of fear [29]. In this study, the participants needed sufficient information on the effectiveness of isolation/quarantine to control the spread of the infection, duration of the isolation/quarantine period, and regular, accurate, and up-to-date information on COVID-19 during their isolation/quarantine period. Lin et al. (2010) reported that individuals who were isolated/quarantined for SARS felt stigmatized when they were quarantined [51]. Probably, health education about the disease and the motivation for isolation/quarantine provided to the general public might help reduce social stigma [52]. Many of the participants in this study used strategies to cope with their stressful situation. These strategies included distraction, remaining optimistic, and trials to improve their immunity. Findings of this study were consistent with those reported in a previous study [44]. In the current study, some of the participants reported that they distracted themselves through watching TV, prayers to God, and reading Holy Qur'an. Additionally, some of the participants saw the positive side of the isolation/quarantine as they received support from their families and beloved ones.

All the participants in this study stressed on the importance of religion during the isolation/quarantine period. The participants reported finding new insights into their faith as they recovered from the infection. Most of the participants reported that they believed that stronger faith would protect them from the negative consequences of the disease. Findings of this study were consistent with those reported by Taylor \& Stanton in which religious beliefs shaped feeling relaxed as one would receive rewards from God for the spiritual experiences during isolation/quarantine [53]. In this study, all of the participants had smartphones and other devices to contact their families and beloved ones. This might have helped the participants divert their negative thoughts through support seeking behavior.

\section{Supportive treatment, herbs, and rituals}

At the time of the study, there were no approved drugs to cure COVID-19. Therefore, the participants in this study used herbal medicines in a trial to improve their immunity and alleviate the symptoms of the disease. Findings of this study were consistent with previous studies in which patients tried herbal medicine to alleviate symptoms of viral infections $[54,55]$. Some herbal medicines are known to contain certain active compounds that exhibit antiviral, antimicrobial, anti-inflammatory, antioxidant, and immunostimulatory activities [56]. These herbal medicines include those derived from echinacea, quinine and curcumin [56]. Probably, these herbal medicines can help modulate the immune responses and help alleviate the symptoms associated with COVID-19. In absence of solid scientific basis, herbal medicines are extensively offered in the markets claiming to cure certain diseases for which modern drugs are not available/approved. During the current pandemic, many herbal medicines are being sold with a claim to cure COVID-19. The participants in this study might have been affected by the heavy advertising of these medicines. Rigorously designed clinical trials are still needed to investigate if such herbal medicines can be helpful in the treatment of COVID-19.

\section{Conclusion}

Findings of this qualitative study described lived experiences of COVID-19 survivors. Survivors who were interviewed in this study recounted devastating experiences with regard to their mental health, social stigmatization, feeling guilt, shame, and hesitant to regain contact with others. Mental health issues should be addressed as a part of the care plan for patients with COVID-19. More studies are still needed to investigate if introducing mental healthcare providers to the care team of patients with COVID-19 can improve the experiences of the patients.

Page 9/13 


\section{Abbreviations}

COVID-19: Coronavirus disease of 2019

COREQ: Consolidated criteria for reporting qualitative research

IRB: Institutional Review Board

NIS: New Israeli Shekel

WHO: World Health Organization

\section{Declarations}

\section{Ethics approval and consent to participate}

The study was conducted in adherence to the ethical consideration in the Declaration of Helsinki and the international guidelines of medical research. AnNajah National University's Institutional Review Board (IRB) approved the procedure of protection of human subjects that was followed in this study. The participants provided verbal consent before they were interviewed. Confidentiality of the participants was maintained and no information leading to the identification of the participants was disclosed. No body other than the researchers had access to the recorded materials. All data related to this study were stored in a closed cabinet.

\section{Consent for publication}

Not applicable.

\section{Availability of data and materials}

All data relevant to this work are included within the manuscript or in the additional file as supplementary materials.

\section{Competing interests}

All authors report no competing interests.

Funding

This study did not receive any specific funding.

\section{Authors' Contributions}

AA was involved in the conception and design of the work, in the data acquisition, analysis and interpretation of data, drafting and final approval the manuscript. Fadi AlZiben , Mohammad Abu Rajab and Mahdia Alkony were involved in the data acquisition, analysis, drafting the work and final approval of the version to be published.

\section{Acknowledgements}

Authors would like to thank the patients who participated in the study.

\section{References}

1. Novel Coronavirus (2019-nCoV) Situation Report [https://www.who.int/docs/default-source/coronaviruse/situation-reports/20200228-sitrep-39-covid19.pdf?sfvrsn=aa1b80a7_2]

2. Chan JF, Yuan S, Kok KH, To KK, Chu H, Yang J, Xing F, Liu J, Yip CC, Poon RW et al: A familial cluster of pneumonia associated with the 2019 novel coronavirus indicating person-to-person transmission: a study of a family cluster. Lancet 2020, 395(10223):514-523.

3. Shim E, Tariq A, Choi W, Lee Y, Chowell G: Transmission potential and severity of COVID-19 in South Korea. International Journal of Infectious Diseases 2020, 93:339-344.

4. Huang C, Wang Y, Li X, Ren L, Zhao J, Hu Y, Zhang L, Fan G, Xu J, Gu X et al: Clinical features of patients infected with 2019 novel coronavirus in Wuhan, China. The Lancet 2020, 395(10223):497-506.

5. Liu W, Liu J: Living with COVID-19: a phenomenological study of hospitalised patients involved in family cluster transmission. $B M J$ open 2021 , 11(2):e046128.

6. Sahoo S, Mehra A, Suri V, Malhotra P, Yaddanapudi LN, Dutt Puri G, Grover S: Lived experiences of the corona survivors (patients admitted in CoVID wards): A narrative real-life documented summaries of internalized guilt, shame, stigma, anger. Asian journal of psychiatry $2020,53: 102187$.

7. Falvo I, Zufferey MC, Albanese E, Fadda M: Lived experiences of older adults during the first COVID-19 lockdown: A qualitative study. PLOS ONE 2021, 16(6):e0252101. 
8. Shaban RZ, Nahidi S, Sotomayor-Castillo C, Li C, Gilroy N, O'Sullivan MVN, Sorrell TC, White E, Hackett K, Bag S: SARS-CoV-2 infection and CoVID-19: The lived experience and perceptions of patients in isolation and care in an Australian healthcare setting. Am J Infect Contro/ 2020, 48(12):1445-1450.

9. Giorgi A: Sketch of a psychological phenomenological method. Phenomenology and psychological research 1985:8-22.

10. Giorgi A, Fischer WF, Von Eckartsberg R: Duquesne studies in phenomenological psychology, vol. 1: Duquesne University Press Pittsburgh; 1971.

11. Kvale S, Brinkmann S: Interviews: Learning the craft of qualitative research interviewing: sage; 2009.

12. Weiss RS: Learning from strangers: The art and method of qualitative interview studies: Simon and Schuster; 1995.

13. Korstjens I, Moser A: Series: Practical guidance to qualitative research. Part 4: Trustworthiness and publishing. European Journal of General Practice 2018, 24(1):120-124.

14. Ashworth P: "Bracketing" in phenomenology: Renouncing assumptions in hearing about student cheating. International Journal of Qualitative Studies in Education 1999, 12(6):707-721.

15. Robertson E, Hershenfield K, Grace SL, Stewart DE: The Psychosocial Effects of Being Quarantined following Exposure to SARS: A Qualitative Study of Toronto Health Care Workers. The Canadian Journal of Psychiatry 2004, 49(6):403-407.

16. Association WM: World Medical Association Declaration of Helsinki: ethical principles for medical research involving human subjects. The Journal of the American College of Dentists 2014, 81(3):14-18.

17. Wang W, Tang J, Wei F: Updated understanding of the outbreak of 2019 novel coronavirus (2019-nCoV) in Wuhan, China. Journal of medical virology 2020, 92(4):441-447.

18. Cheng SK, Wong CW, Tsang J, Wong KC: Psychological distress and negative appraisals in survivors of severe acute respiratory syndrome (SARS) Psychological medicine 2004, 34(7):1187-1195.

19. Mak IW, Chu CM, Pan PC, Yiu MG, Chan VL: Long-term psychiatric morbidities among SARS survivors. General hospital psychiatry 2009, 31(4):318-326.

20. Almutairi AF, Adlan AA, Balkhy HH, Abbas OA, Clark AM: "It feels like I'm the dirtiest person in the world.": Exploring the experiences of healthcare providers who survived MERS-CoV in Saudi Arabia. Journal of infection and public health 2018, 11(2):187-191.

21. Jeong H, Yim HW, Song Y-J, Ki M, Min J-A, Cho J, Chae J-H: Mental health status of people isolated due to Middle East Respiratory Syndrome. Epidemiol Health 2016, 38:e2016048-e2016048.

22. Hollander JE, Carr BG: Virtually Perfect? Telemedicine for Covid-19. New England Journal of Medicine 2020, 382(18):1679-1681.

23. Hawryluck L, Gold WL, Robinson S, Pogorski S, Galea S, Styra R: SARS control and psychological effects of quarantine, Toronto, Canada. Emerging infectious diseases 2004, 10(7):1206-1212.

24. Wakam GK, Montgomery JR, Biesterveld BE, Brown CS: Not Dying Alone - Modem Compassionate Care in the Covid-19 Pandemic. New England Journal of Medicine 2020, 382(24):e88.

25. Ward D: Infection control: reducing the psychological effects of isolation. British Journal of Nursing 2000, 9(3):162-170.

26. Banerjee D: The COVID-19 outbreak: Crucial role the psychiatrists can play. Asian journal of psychiatry 2020, 50:102014.

27. Organization WH: Mental health and psychosocial considerations during the COVID-19 outbreak, 18 March 2020. In.: World Health Organization; 2020.

28. Li W, Yang Y, Liu ZH, Zhao YJ, Zhang Q, Zhang L, Cheung T, Xiang YT: Progression of Mental Health Services during the COVID-19 Outbreak in China. International journal of biological sciences 2020, 16(10):1732-1738.

29. Xiang Y-T, Yang Y, Li W, Zhang L, Zhang Q, Cheung T, Ng CH: Timely mental health care for the 2019 novel coronavirus outbreak is urgently needed. The Lancet Psychiatry 2020, 7(3):228-229.

30. Grover S, Dua D, Sahoo S, Mehra A, Nehra R, Chakrabarti S: Why all COVID-19 hospitals should have mental health professionals: The importance of mental health in a worldwide crisis! Asian journal of psychiatry 2020, 51:102147.

31. Das N: Psychiatrist in post-COVID-19 era - Are we prepared? Asian journal of psychiatry 2020, 51:102082.

32. Ren LL, Wang YM, Wu ZQ, Xiang ZC, Guo L, Xu T, Jiang YZ, Xiong Y, Li YJ, Li XW et al: Identification of a novel coronavirus causing severe pneumonia in human: a descriptive study. Chinese medical journal 2020, 133(9):1015-1024.

33. Carlos WG, Dela Cruz CS, Cao B, Pasnick S, Jamil S: Novel Wuhan (2019-nCoV) Coronavirus. American journal of respiratory and critical care medicine 2020, 201(4):P7-P8.

34. Wu C, Chen X, Cai Y, Xia J, Zhou X, Xu S, Huang H, Zhang L, Zhou X, Du C et al: Risk Factors Associated With Acute Respiratory Distress Syndrome and Death in Patients With Coronavirus Disease 2019 Pneumonia in Wuhan, China. JAMA internal medicine 2020, 180(7):934-943.

35. Liu K, Fang YY, Deng Y, Liu W, Wang MF, Ma JP, Xiao W, Wang YN, Zhong MH, Li CH et al: Clinical characteristics of novel coronavirus cases in tertiary hospitals in Hubei Province. Chinese medical journal 2020, 133(9):1025-1031.

36. Kim JY, Choe PG, Oh Y, Oh KJ, Kim J, Park SJ, Park JH, Na HK, Oh MD: The First Case of 2019 Novel Coronavirus Pneumonia Imported into Korea from Wuhan, China: Implication for Infection Prevention and Control Measures. Journal of Korean medical science 2020, 35 (5):e61.

37. Holshue ML, DeBolt C, Lindquist S, Lofy KH, Wiesman J, Bruce H, Spitters C, Ericson K, Wilkerson S, Tural A et al: First Case of 2019 Novel Coronavirus in the United States. The New England journal of medicine 2020, 382(10):929-936.

38. Rothan HA, Byrareddy SN: The epidemiology and pathogenesis of coronavirus disease (COVID-19) outbreak. Journal of autoimmunity $2020,109: 102433$.

39. Fife BL, Wright ER: The Dimensionality of Stigma: A Comparison of Its Impact on the Self of Persons with HIV/AIDS and Cancer. Journal of Health and Social Behavior 2000, 41(1):50-67.

40. Scambler G: Health-related stigma. Sociology of Health \& IIIness 2009, 31(3):441-455. 
41. Raghavan V, Jabbarkhail D, Ahmady A: Health worker's perception survey on COVID 19: Knowledge, Perception, and Practice Survey of health workers in Eight Provinces of Afghanistan, 2020. In.; 2020.

42. Ahmad AR, Murad HR: The Impact of Social Media on Panic During the COVID-19 Pandemic in Iraqi Kurdistan: Online Questionnaire Study. Journal of medical Internet research 2020, 22(5):e19556.

43. Huang X, Li H, Meyers K, Xia W, Meng Z, Li C, Bai J, He S, Cai W, Huang C et al: Burden of sleep disturbances and associated risk factors: A cross-sectional survey among HIV-infected persons on antiretroviral therapy across China. Scientific Reports 2017, 7(1):3657.

44. Cava MA, Fay KE, Beanlands HJ, McCay EA, Wignall R: The experience of quarantine for individuals affected by SARS in Toronto. Public health nursing 2005, 22(5):398-406.

45. Desclaux A, Badji D, Ndione AG, Sow K: Accepted monitoring or endured quarantine? Ebola contacts' perceptions in Senegal. Social science \& medicine 2017, 178:38-45.

46. Marjanovic Z, Greenglass ER, Coffey S: The relevance of psychosocial variables and working conditions in predicting nurses' coping strategies during the SARS crisis: An online questionnaire survey. International Journal of Nursing Studies 2007, 44(6):991-998.

47. Manuell M-E, Cukor J: Mother Nature versus human nature: public compliance with evacuation and quarantine. Disasters 2011, 35(2):417-442.

48. Barbisch D, Koenig KL, Shih FY: Is There a Case for Quarantine? Perspectives from SARS to Ebola. Disaster medicine and public health preparedness 2015, 9(5):547-553.

49. McAloon C, Collins Á, Hunt K, Barber A, Byrne AW, Butler F, Casey M, Griffin J, Lane E, McEvoy D et al: Incubation period of CovID-19: a rapid systematic review and meta-analysis of observational research. BMJ open 2020, 10(8):e039652.

50. Xiao C: A Novel Approach of Consultation on 2019 Novel Coronavirus (COVID-19)-Related Psychological and Mental Problems: Structured Letter Therapy. Psychiatry investigation 2020, 17(2):175-176.

51. Lin ECL, Peng YC, Hung Tsai JC: Lessons learned from the anti-SARS quarantine experience in a hospital-based fever screening station in Taiwan. American Journal of Infection Control 2010, 38(4):302-307.

52. Berkman LF, Syme SL: Social networks, host resistance, and mortality: a nine-year follow-up study of Alameda County residents. American journal of epidemiology 1979, 109(2):186-204.

53. Taylor SE, Stanton AL: Coping Resources, Coping Processes, and Mental Health. Annual Review of Clinical Psychology 2007, 3(1):377-401.

54. Zhang Y, Ma ZF: Impact of the COVID-19 Pandemic on Mental Health and Quality of Life among Local Residents in Liaoning Province, China: A CrossSectional Study. International Journal of Environmental Research and Public Health 2020, 17(7):2381.

55. Sharma M, Anderson SA, Schoop R, Hudson JB: Induction of multiple pro-inflammatory cytokines by respiratory viruses and reversal by standardized Echinacea, a potent antiviral herbal extract. Antiviral Research 2009, 83(2):165-170.

56. Kocaadam B, Şanlier N: Curcumin, an active component of turmeric (Curcuma longa), and its effects on health. Critical Reviews in Food Science and Nutrition 2017, 57(13):2889-2895.

\section{Table}


Table 1

Sociodemographic and health details of the interviewees

\begin{tabular}{|c|c|c|c|c|c|c|c|c|c|c|c|}
\hline$\#$ & $\begin{array}{l}\text { Age } \\
\text { (years) }\end{array}$ & Gender & $\begin{array}{l}\text { Place of } \\
\text { residence }\end{array}$ & $\begin{array}{l}\text { Marital } \\
\text { status }\end{array}$ & $\begin{array}{l}\text { Number } \\
\text { of } \\
\text { offspring }\end{array}$ & $\begin{array}{l}\text { Number } \\
\text { of family } \\
\text { members }\end{array}$ & Education & Smoking & Occupation & Previous history & $\begin{array}{l}\text { Monthly } \\
\text { income } \\
\text { (NIS) }\end{array}$ \\
\hline P1 & 25 & Male & Tulkarem & Married & 0 & 2 & $\begin{array}{l}\text { University } \\
\text { degree }\end{array}$ & Yes & Nurse & $\begin{array}{l}\text { Gastro esophageal } \\
\text { reflex and Asthma }\end{array}$ & $\geq 3000$ \\
\hline P2 & 48 & Male & Nablus & Married & 3 & 5 & School & No & Police officer & $\begin{array}{l}\text { High blood pressure, } \\
\text { hyperlipidemia and } \\
\text { hypercholesterolemia }\end{array}$ & $\geq 3000$ \\
\hline P3 & 27 & Male & Tulkarem & Single & 0 & 0 & $\begin{array}{l}\text { University } \\
\text { degree }\end{array}$ & No & Nurse & ND & $\geq 3000$ \\
\hline P4 & 49 & Male & Tulkarem & Married & 4 & 6 & $\begin{array}{l}\text { University } \\
\text { degree }\end{array}$ & No & Businessman & ND & $\geq 3000$ \\
\hline P5 & 50 & Female & Tulkarem & Married & 5 & 7 & $\begin{array}{l}\text { University } \\
\text { degree }\end{array}$ & No & $\begin{array}{l}\text { School } \\
\text { teacher }\end{array}$ & Hypertension & $\geq 3000$ \\
\hline P6 & 48 & Female & Nablus & Married & 8 & 10 & $\begin{array}{l}\text { University } \\
\text { degree }\end{array}$ & No & Midwife & ND & $\geq 3000$ \\
\hline P7 & 29 & Male & Nablus & Single & 0 & 1 & $\begin{array}{l}\text { University } \\
\text { degree }\end{array}$ & No & Secretary & ND & $\begin{array}{l}2000- \\
3000\end{array}$ \\
\hline P8 & 38 & Male & Nablus & Married & 2 & 4 & School & Yes & Carpenter & ND & $\geq 3000$ \\
\hline P9 & 35 & Male & Bethlehem & Married & 3 & 5 & $\begin{array}{l}\text { University } \\
\text { degree }\end{array}$ & No & Nurse & ND & $\geq 3000$ \\
\hline P10 & 28 & Male & Nablus & Single & 0 & 5 & $\begin{array}{l}\text { University } \\
\text { degree }\end{array}$ & No & IT & ND & $\geq 3000$ \\
\hline P11 & 26 & Female & Ramallah & Single & 0 & 11 & $\begin{array}{l}\text { University } \\
\text { degree }\end{array}$ & No & ND & ND & ND \\
\hline P12 & 26 & Male & Jenin & Single & 0 & 5 & $\begin{array}{l}\text { University } \\
\text { degree }\end{array}$ & No & Nurse & ND & $\geq 3000$ \\
\hline P13 & 31 & Male & Hebron & Married & 2 & 6 & $\begin{array}{l}\text { University } \\
\text { degree }\end{array}$ & Yes & Nurse & ND & $\geq 3000$ \\
\hline P14 & 50 & Female & Nablus & Married & 5 & 7 & $\begin{array}{l}\text { University } \\
\text { degree }\end{array}$ & No & $\begin{array}{l}\text { School } \\
\text { teacher }\end{array}$ & ND & $\geq 3000$ \\
\hline P15 & 25 & Male & Nablus & Single & 0 & 0 & $\begin{array}{l}\text { University } \\
\text { degree }\end{array}$ & No & Police officer & ND & $\geq 3000$ \\
\hline P16 & 30 & Male & Nablus & Single & 0 & 5 & $\begin{array}{l}\text { University } \\
\text { degree }\end{array}$ & Yes & $\begin{array}{l}\text { School } \\
\text { teacher }\end{array}$ & ND & 2500 \\
\hline P17 & 26 & Male & Nablus & Single & 0 & 5 & $\begin{array}{l}\text { University } \\
\text { degree }\end{array}$ & No & IT & ND & $\geq 3000$ \\
\hline P18 & 55 & Female & Nablus & Married & 3 & 4 & $\begin{array}{l}\text { University } \\
\text { degree }\end{array}$ & No & $\begin{array}{l}\text { School } \\
\text { teacher }\end{array}$ & ND & $\geq 3000$ \\
\hline P19 & 49 & Female & Ramallah & Married & 4 & 6 & $\begin{array}{l}\text { University } \\
\text { degree }\end{array}$ & Yes & $\begin{array}{l}\text { School } \\
\text { teacher }\end{array}$ & ND & $\geq 3000$ \\
\hline P20 & 45 & Male & Nablus & Married & 3 & 5 & $\begin{array}{l}\text { University } \\
\text { degree }\end{array}$ & No & $\begin{array}{l}\text { School } \\
\text { teacher }\end{array}$ & ND & $\geq 3000$ \\
\hline
\end{tabular}

\section{Supplementary Files}

This is a list of supplementary files associated with this preprint. Click to download.

- SupplementarymaterialsBMC.docx 